\title{
Real Rates of Return and Pension Funding - Some Preliminary Considerations *
}

\author{
by Richard Hemming **
}

\section{Introduction}

In $1975111 / 2$ million employees in the UK, about one half of the total workforce, were members of a pension scheme operated separately from the universal social insurance scheme. The majority of these schemes are backed by explicit pension funds into which contributions are paid, where they are accumulated with interest, and from which pensions are paid. For many of these individuals the entitlement to a private pension is the most valuable asset they own.

The vast majority of members are in schemes (some $98 \%$ in 1975) which are operated according to a "defined benefit principle" - that is, either the pension to be received, or the relationship between the pension and some quantifiable individual characteristic, is specified. The pension is not determined by the investment performance of the pension fund. These plans can be distinguished from those operated according to the "defined contribution principle", where it is the contribution, or a rule governing its determination, that is specified. Accumulated contributions at retirement are used to purchase an annuity. The investment performance of the pension fund is therefore crucial in determining the pension paid. Attention will be focused only on the former category.

As typically specified, defined benefit pensions payable on the basis of a period of employment in one job depend upon two characteristics of an individual's work record - length of service and salary close to retirement, either final salary or an average of the last few years. The contributions required to finance these pensions are usually collected as some fixed percentage of gross salary. In general these are divided between employees and employers, but sometimes they are paid wholly by employers. However, this is only their formal incidence. The effective incidence can be, and almost certainly is, very different and the exposition of this paper is considerably simplified if employees are assumed to fully bear all contributions.

* An earlier version of this paper was presented at the 1980 Summer Institute held at the NBER in Cambridge, M.A. and at the Seventh Seminar of the European Group of Risk and Insurance Economists, held at the University of Nottingham in September 1980.

** Institute for Fiscal Studies, London. 
Given a defined benefit formula, a large number of factors come into play in determining the appropriate contribution rate. The aim of this paper is to suggest that one consideration far outweighs the others, not only individually but also in total. This is the assumed long run real rate of return earned by pension contributions. Estimated contribution rates are also wildly sensitive to variations in this assumption. Indeed overestimating the real rate of return by only one percentage point can quite severely impair the ability of schemes to meet the pension promises to which they are committed without significant additional funding or marked alterations in the provisions of the pension contract. Given this possibility, and the importance of pension wealth to scheme members, it seems likely that the way in which pension contributions are determined, and the scope for error in their calculation, will be of some interest. Only a rudimentary understanding of the actuarial underpinnings of a pension scheme's financial planning is necessary to gain some insight into these often uninviting questions.

\section{Actuarial aspects of pension scheme financing}

Assume that an employer has decided to introduce a pension scheme for the existing workforce i.e. no new employees will be admitted into the scheme. After the package of benefits to be offered has been agreed the required contribution rate can only be determined once certain crucial actuarial considerations have been taken into account. These will be considered under three broad headings, only the first two of which have any bearing on the subject of this paper: pension costs ; the actuarial basis ; and the valuation basis.

\subsection{Pension costs}

Assumptions have to be made about a range of factors affecting the future growth of the pension fund and the scheme liabilities. Assumptions which imply that the fund will grow relatively fast lead to low pension costs (a relatively low contribution rate) while assumptions which imply that liabilities are built up relatively fast lead to high pension costs. The relevant factors are summarised in Table 2.1 - those listed above the break in the table are the most important.

The first problem is to determine the pension that will be payable to each employee at retirement age. A certain amount of factual data is available to help in doing this. The age and sex distribution of the initial scheme membership, their present earnings, and complete employment history with the current employer will typically be available. However, if pension contributions and benefits are income related, and, in particular, the benefit is a function of income close to retirement, then a view has to be formed about each individual's salary progression through to retirement. This can be split into two components. The first is that which can be expected to occur due to normal progress through jobs involving different levels of skill and responsibility - this can be fairly reliably predicted. The second is due to the general growth of all earnings. Clearly, the higher the assumed rates of earnings growth the more expensive the pension will be to provide. 
Table 2.1 : Determinants of pension costs

\begin{tabular}{|ll|}
\hline $\begin{array}{l}\text { Factors increasing } \\
\text { pension costs }\end{array}$ & $\begin{array}{l}\text { Factors decreasing } \\
\text { pension costs }\end{array}$ \\
\hline $\begin{array}{l}\text { Earnings growth } \\
\text { Price inflation }\end{array}$ & $\begin{array}{l}\text { High rates of return } \\
\text { High mortality }- \text { in retirement }\end{array}$ \\
\hline $\begin{array}{l}\text { Ill-health } \\
\text { Widows and dependants }\end{array}$ & $\begin{array}{l}\text { Late retirement } \\
\text { Withdrawal }\end{array}$ \\
Early retirement & Redundancy \\
\hline
\end{tabular}

In an inflationary environment the real value of pensions in payment decline, and it is normal for the pensioner to be compensated for this in some way. Only in the best schemes is the pension fully protected (some $46 \%$ of pensions are indexed). However, many pensioners now regularly receive increases in their pensions (some $93 \%$ in 1975), and this too raises pensions costs.

Invested contributions will earn interest and the capital value of the assets which they are used to purchase will also change. High rates of return reduce pension costs.

An actuary's view about future rates of earnings growth, price inflation and rates of return constitute his " economic" assumptions. Certain purely " actuarial " assumptions concerning, most crucially, mortality are also made. These contribute significantly to the view that is formed about the number of individuals who will leave the scheme, either before or after retirement.

All scheme members will die, most in, but a significant proportion before retirement. The number of deaths in service is estimated from mortality tables specific to the group of employees being considered while the number of deaths in retirement is typically estimated from general mortality tables.

As regards the other assumptions listed the reasons for their effect should be fairly obvious, and with the exception of withdrawal, that is employees changing jobs, they will henceforth be ignored. Attention is to be focused on the relative importance of the "economic" and "actuarial" assumptions in contribution calculations. Now the mortality estimates are extremely reliable - only where the employment history is short or its characteristics unusual are serious errors at all likely. However, predicting the elements of the "economic" assumptions requires a degree of clairvoyance that is certainly not bestowed upon the average actuary. It should not then appear too surprising if it were to transpire that the net outcome of actuarial advice is the more than occasional financial disaster. In fact, the recent history of pension scheme financing suggests that such an occurrence is extremely rare. To understand why this is the case, the way in which actuaries handle these uncertainties will be explained. 


\subsection{Actuarial basis}

It is perhaps reassuring to learn that few actuaries are likely to believe that rates of return, earnings growth, price inflation and withdrawal can be predicted with any confidence. Unfortunately, it may come as cold comfort to know how actuaries handle the problem this creates.

Reliance is placed upon what is known as the "actuarial basis". This refers to the assumptions that are made about the long run relationship between the rates of return, earnings growth, price inflation and withdrawal. Although each of these rates may be difficult to predict individually, it is their net impact that is important in deciding the financial strategy of a pension fund and which has to be predicted. The "actuarial basis" therefore relies on compensating changes within the set of rates to maintain its accuracy. In the past this approach has worked quite satisfactorily frequent bankruptcies of pension funds have not been noted, although some hasty financial adjustments have been needed to some funds in recent years.

For many years the most common actuarial basis involved the following specification. A low rate of return was usually assumed, in conjunction with a low withdrawal rate and no earnings growth or price inflation. This boiled down to assuming about a $3 \%$ real rate of return to the fund. However, during the 1950's and 1960's earnings grew quite markedly, implying unanticipated increases in liabilities. But to counteract this investment returns exceeded their expected level, as did withdrawals. The latter benefit the fund since withdrawing members usually only had their contributions refunded to them. Thus although no element of the actuarial basis was at all accurate, pension costs were not affected and pension funds remained financially secure.

In recent years there has been a shift towards employing more realistic predictions of the elements of the actuarial basis. The reasoning behind this has little to do with the restructuring of the actuarial basis, or at least would appear not to have. Even with the high rates of earnings growth and price inflation in the 1970's it has still been assumed that the rate of return to funds will exceed the rate of price inflation by up to $3 \%$. However, the usual assumption is $2 \%$ or $1 \%$. These changes have taken place mainly to maintain confidence in actuarial estimates. That is, actuarial advice will be more readily accepted if an actuary says that a long run rate of price inflation of $7 \%$ is being assumed rather than $0 \%$ when the observed rate in recent years has been around $10 \%$. Similarly, if the real rate of return is widely reported to be negative, the actuary offering $1 \%$ or $2 \%$ as his assumed rate may be felt to be more in touch than one offering $3 \%$.

Although the chosen actuarial basis has proved satisfactory in the past, there is sufficient reason to believe that this good fortune may not persist for much longer. Indeed, recent tax legislation requires that eligibility for tax-advantaged treatment of pension schemes only be granted to those that are adequately funded. Actuarial investigations of schemes attempting to comply with this legislation have revealed some large unfunded liabilities with the existing actuarial basis. Moreover, it is likely that these unfunded liabilities are under valued, and that some schemes which believe they are adequately funded will turn out to be under funded. The reason for this is that long run real rates of return to the typical pension fund portfolio are certainly 
not as large as $3 \%$, and may even be negative. In addition, the situation is likely to get worse as a major source of profit, withdrawal, has now been partially outlawed as a result of recent social insurance legislation. Many members withdrawing from a pension scheme are now allowed to have their private pensions preserved until retirement.

\subsection{Valuation basis}

Pension funding can be based upon a closed fund or a continuing fund valuation basis. With the former the aim is to ensure that at the present date or some date in the future the fund is sufficient to meet the benefits that members have accrued under the scheme. With the latter, account is taken of the benefits that are projected to accrue to all members of the scheme should they remain in it until retirement. The latter is more consistent with the approach set out at the beginning of this paper - it allows the fixed contribution rate necessary to cover the cost of projected benefits to be estimated. Note that, with earnings growth and price inflation, the continuing fund valuation basis implies a higher degree of funding than the closed fund valuation basis.

The contribution rate can be calculated on the basis of individual or aggregate costs. The distinction between these two methods is the following. The individual method treats each member of the scheme individually, and finds the costs of each one's personal pension, and the required contribution rate. The aggregate method involves the calculation of a contribution rate for a hypothetical representative member, of average age, service and earnings. Estimates in this paper will be based on the second of these methods.

\section{Real rates of return in the UK}

For many years now the real rates of return on a wide range of financial assets in the UK have been negative. Some people have recognised that they are likely to remain so for some considerable time, and have modified their own behaviour to accommodate this. For example, no insurance company will commit itself to offering an index linked pension, at any price, and the Government strictly controls the availability of securities offering a zero real rate of return. Yet actuaries working in both the private and public sectors persist in assuming that real rates of return are positive, and may be as high as $3 \%$. How can such a view be justified?

It is clear that only the most myopic of actuaries would base his assessment of the expected long run real rate of return on those rates observed in the current year or over the last few. The variations that would emerge from year to year are too large to render this a sensible procedure. It is the single real rate of return, which if it prevailed in every period over, say, thirty years, would replicate the changes occurring in a fund between the beginning and end of the period that should properly be estimated. However, this alone is not sufficient, since it may be the case that real rates are generally higher or lower towards the end of the period. Given that the actuary is searching for a guide to the real rate of return that ought to be assumed for the next ten, twenty, or thirty years more weight should perhaps be placed on more recent experience. 
Table 3.1 gives some guide to the recent investment performance of life and pension funds in the UK. At the end of 1978 pension funds held $53 \%$ of their assets in equities, $21 \%$ in gilt edged and $17 \%$ in property. Thus the performance of a typical pension fund portfolio is determined by the performance of equities and gilt edged, and mainly the former. In a world where pension scheme liabilities are fixed in money terms it would be the gilt edged market that could be expected to dominate. However, inflation has led to shift towards equities, in the hope that the performance of the business sector would match the growth of pension liabilities. For many years this proved to be a successful policy but declining profitability in recent years has implied low returns to equities. Life and pension funds now find it extremely difficult to earn a return in excess of the rate of price inflation. This is clearly demonstrated in the table.

Table $3.1:$ Return on life and pension funds 1970-79 (\%)

\begin{tabular}{cccccc}
\hline Year & $\begin{array}{c}\text { Rent, interest } \\
\text { and dividends }\end{array}$ & $\begin{array}{c}\text { Capital } \\
\text { appreciation }\end{array}$ & $\begin{array}{c}\text { Total } \\
\text { return }\end{array}$ & $\begin{array}{c}\text { Annual } \\
\text { change in } \\
\text { price index }\end{array}$ & $\begin{array}{c}\text { Annual } \\
\text { change in } \\
\text { earnings index }\end{array}$ \\
\hline 1970 & 6.8 & 0 & 6.8 & 6.9 & 12.7 \\
1971 & 6.6 & 9.3 & 16.5 & 9.0 & 10.6 \\
1972 & 6.4 & 4.1 & 10.7 & 6.3 & 15.7 \\
1973 & 7.1 & -11.7 & -5.4 & 10.5 & 12.4 \\
1974 & 8.7 & -22.8 & -16.1 & 19.2 & 29.1 \\
1975 & 9.0 & 15.5 & 25.9 & 24.8 & 19.0 \\
1976 & 8.9 & -1.2 & 7.6 & 15.1 & 11.4 \\
1977 & 6.3 & 23.0 & 30.7 & 12.1 & 10.5 \\
1978 & 8.2 & -1.9 & 6.1 & 8.3 & 15.1 \\
1979 & 9.0 & 4.0 & 13.4 & 17.2 & 19.2
\end{tabular}

Source : Lloyds Bank Economic Bulletin, 19, July 1980 (derived from Personal Sector Balance Sheets and the National Income and Expenditure Blue Book, 1979). Department of Employment Gazette, various years.

Given that the liabilities of life insurance companies are, to a large extent, fixed in nominal terms the life funds tend to hold a larger proportion of gilt edged and a smaller proportion of equities. Although the differences are not large - they hold $35 \%$ in equities and $25 \%$ in gilt edged - Table 3.1 might not be fully representative of the typical pension fund. However, in a recent article in the "Investor's Chronicle" it was suggested that a typical managed pension fund, the holdings of which were not specified but were unlikely to be far removed from those described above, set up in January 1970, would have earned an annual rate of return of $11.3 \%$ by December 1979. This is equivalent to a price deflated real rate of return of $-1.6 \%$. Other estimates have suggested that the rate of return may have been as low as $9.0 \%$ over a similar period, and the real rate of return even smaller than $-1.6 \%$. 
The figures quoted above are price deflated real rates of return. If earnings and prices increase at the same long run rate then these are relevant to actuarial calculations. However, when they are different the earnings deflated real rate of return has to be taken into account. If pensions are related to salary at retirement and indexed during retirement to an earnings index, it alone is the relevant real rate of return. Now from the data used to construct Table 3.1 it can be shown that the long run rate of price inflation from January 1970 to December 1979 has been $13.0 \%$ while the long run rate of earnings escalation has been $15.3 \%$. The earnings deflated real rate of return to the typical pension fund described in Table 3.1 is therefore around $-4 \%$. It is usually found that pensions at retirement are related to earnings close to retirement while pensions in payment are, on average, partially indexed to prices. This makes it difficult to compute the precise real rate of return a pension fund has to make. But it does seem fairly likely that most pension funds have been making a rate of return below that necessary to adequately fund their liabilities, and some have been making fairly large negative real returns.

Although no great faith is to be placed in the precision of the above estimates, they do sow the seeds of doubt about the normal actuarial assumption that pension funds will earn a return of $2-3 \%$ in excess of the rate of earnings growth or price inflation. It seems likely that this difference is much smaller and it may even be negative. Given these possibilities it is interesting to know the impact of incorrectly forecasting the price and earnings deflated real rates of return on the ability of pension schemes to meet their liabilities with the funds that have been accumulated.

\section{A simple model of a pension scheme}

To analyse the impact of variations in the real rate of return a simple model of a pension scheme will be employed. It will be assumed that a pension is to be provided for a representative individual aged $a$ at the time he joins the scheme. In every period of employment the proportion $\alpha$ of gross earnings is paid into the scheme. Initial earnings are $y_{a}$ and are expected to grow at a constant exponential rate $g$. There are no merit increases in earnings. Income at retirement, fixed at a date $T$, is therefore given by $y_{T}=y_{a} e^{g(T-a)}$. Contributions are accumulated in a pension fund which earns interest at a constant rate $r$. Future income is discounted at the same rate.

On retirement a pension equal to $\beta y_{T}$ becomes payable, where $\beta$ depends upon the length of service. In particular, it will be assumed that the pension is $1 / 60$ th of final earnings for each year of service. Pensions in payment are indexed to prices, the rate of price inflation being exactly equal to the rate of earnings growth.

The problem is to find the contribution rate $a$ which will finance such a scheme. Now for a given life expectancy, $L$, the accumulated pension fund at retirement is given by

$$
F=\int_{a}^{T} \alpha y_{a} e^{g(t-a)} e^{r(T-t)} d t
$$


and the present value of future benefits at retirement is

$$
B=\int_{T}^{L} \beta y_{a} e^{g(T-a)} e^{g(t-T)} e^{-r(t-T)} d t
$$

If the scheme can be administered at no cost the appropriate contribution rate is derived by setting $F=B$ and solving for $\alpha$. From (4.1) and (4.2).

$$
\alpha \int_{a}^{T} e^{-(r-g) t} d t=\beta \int_{T}^{L} e^{-(r-g) t} d t
$$

which can be written

$$
\alpha\left[-\frac{1}{(r-g)} e^{-(r-g) t}\right]_{a}^{T}=\beta\left[-\frac{1}{(r-g)} e^{-(r-g) t}\right]_{T}^{L}
$$

or

$$
\alpha\left[\frac{e^{-(r-g) a}-e^{-(r-g) \bar{T}}}{(r-g)}\right]=\beta\left[\frac{e^{-(r-g) T}-e^{-(r-g) \bar{L}}}{(r-g)}\right] .
$$

Solving for $\alpha$ yields

$$
\alpha=\beta e^{(r-g)(a-T)}\left[\frac{1-e^{(r-g)(T-L)}}{1-e^{(r-g)(a-T)}}\right] .
$$

Now this is an interesting expression because it reveals that the rate of return and the rate of earnings growth enter only in the form $(r-g)$. Thus no matter what the levels of $r$ and $g$ only the difference matters. However, it should be pointed out that this is a property of the model specified in continuous time. In the discrete time analogue of this model

$$
\alpha=\beta \frac{(1+r)^{a-T}}{(1+g)}\left[\frac{1-\frac{(1+r)^{T-L}}{(1+g)}}{1-\frac{(1+r)^{a-T}}{(1+g)}}\right]
$$

and the solution for $\alpha$ depends upon $(1+r) /(1+g)$. Only if $r$ and $g$ are sufficiently small is $(1+r) /(1+g) \approx e^{(r-g)}$.

The financing calculations for this pension scheme are the simplest imaginable, but in a somewhat stylized fashion it is fairly easy to identify what the role of an actuary might be in the running of such a scheme. There are essentially two things for an actuary to do. Firstly, a mortality assumption has to be made. In this simple model this involves the selecting of a value for $L$. Now this is not the way such a contingency should correctly be accommodated - there may be some good reasons for not allowing very young workers to join pension schemes but the fact that their life expectancy is not sufficiently large to see them into retirement is not one. The survival probability for each year of scheme membership should be computed and contributions payable and pensions receivable appropriately discounted. Unfortunately, such an approach complicates the analysis far more than is necessary to establish its major point. 
However, lip service will be paid to the problem by setting $L$ at a value which yields estimates for $\alpha$ which broadly coincide with those generated by the correct procedure employing a discrete time model, which is the usual actuarial practice.

The actuary also makes a judgement as to the excess of the rate of return to the fund over the rate of growth of earnings. The discussion above has indicated that it is an assessment of the long run rate that is appropriate but that there may be reasons to believe that it is not "estimated" at all accurately. The implications of this will now be investigated. In using the above model for this purpose it will be assumed that $a=35$ and $T=65$ so that $\beta=1 / 2$. Note that $y_{a}$ does not have to be specified.

\section{The effect of variations in the real rate of return}

To comment on the sensitivity of actuarial calculations to the choice of the real rate of return (4.6) will be used to compute $\alpha$ for various values of $(r-g)$. These are given in the following table :

Table 5.1

\begin{tabular}{|cccccccc|}
\hline$(r-g)$ & $3 \%$ & $2 \%$ & $1 \%$ & 0 & $-1 \%$ & $-2 \%$ & $-3 \%$ \\
$\alpha$ & $10.4 \%$ & $12.9 \%$ & $16.1 \%$ & $20.0 \%$ & $24.6 \%$ & $30.0 \%$ & $36.5 \%$ \\
\hline
\end{tabular}

the appropriate value for $L$ being 77 . Clearly, the adoption of a real rate of return even one percentage point higher than its true value implies considerable under funding of pension liabilities.

An appealing way of representing the magnitude of the error being made is to assume that $(r-g)$ equals either $2 \%$ or $1 \%$, the values typically employed by actuaries in the private sector. Given that the scheme is supposed to be self financing (4.6) can be used to show, for deviations from the expected real rate of return, the values of $L$ which would imply the same errors in forecasting the contribution rate as those given by Table 5.1. Examples of these are shown below.

Table 5.2

\begin{tabular}{|ccccc|}
\hline Assumed & $(r-g)=$ & $1 \%$ & & \\
Actual & $(r-g)$ & $0 \%$ & $-1 \%$ & $-2 \%$ \\
$L$ & & 80 & 84 & 89 \\
Assumed & $(r-g)=$ & $2 \%$ & & \\
Actual & $(r-g)$ & $1 \%$ & $0 \%$ & $-1 \%$ \\
$L$ & & 80 & 85 & 91 \\
\hline
\end{tabular}

The retirement period lasts for twelve years and a one percentage point over estimate of the real rate of return has the same impact as extending it by $25 \%$, a two percentage point overestimate is equivalent to a more than $50 \%$ increase and a three percentage point overestimate is the equivalent of assuming the retirement period to be more than twice its true length. It is unlikely that the discovery of a cure for cancer could achieve an increase in life expectancy of this sort of magnitude. 
At a fairly simple level the dominance of actuarial assumptions by the economic in pension funding calculations has been clearly established. However, a convincing argument that the implications of the results are extremely serious really requires it to be demonstrated that they have general applicability. In other words, it has to be shown that the results are representative of those that would emerge if the exercise were repeated for the larger and more complex schemes operating in the UK economy. To our knowledge no such exercise has yet been reported (though it has probably been undertaken), but it is hoped that the wider relevance of these findings will eventually be either confirmed or refuted.

\section{Implications of the analysis}

\subsection{Pension scheme funding}

If the actuary's economic assumptions are inappropriate then contributions to pension funds have been too low to finance the benefits that have been promised. Schemes will be under funded to the extent that contributions have fallen below their required level. Maintenance of the agreed terms of the pension contract will clearly require a substantial amount of "topping-up" of the pension fund. Already there are instances of this being necessary. The most publicised case was the payment by British Petroleum of $£ 38$ million, or approximately $5 \%$ of net corporate income, into its pension fund in 1974, a year of unprecedented earnings growth.

Not all companies discovering a price inflation /earnings growth induced unfunded liability need adopt such a strategy. If it has been the usual practice to fund liabilities in advance the degree of funding can be reduced. Existing legislation requires only that those liabilities accrued by scheme members at any point in time are fully funded. The degree of funding can be reduced from that implied by the continuing fund valuation basis. Hence a less demanding valuation basis can be adopted. However, this is merely to delay the problem - with defined benefit plans and earnings growth pension rights accrue very fast late in the working life and contributions have to rise correspondingly. Once funding reaches its minimum degree an unfunded liability has to be corrected in some other manner. Contribution rate can be modified. Either employees or employers can contribute at higher rates in order that unfunded liabilities can be met, and this solution has been widely adopted in the UK to date. An alternative response is to reduce the quality of benefits, say by withdrawing any indexation provision or adjusting the defined benefit formula more directly. The burden of pension provision can also be shifted to the State social insurance scheme. We will now discuss some of these possible reactions.

\subsection{Indexation of pensions}

In the simple model described above it is assumed that the pension in payment is fully indexed. Indexation is not provided without considerable costs being incurred. To see this note that in the absence of indexation (4.3) becomes

$$
a^{*} \int_{a}^{T} e^{-(r-g) t} d t=\beta e^{g T} \int_{T}^{L} e^{-r t} d t
$$


from which it can be shown that

$$
a^{*}=\frac{\beta e^{g T}\left[\frac{\left.e^{-r t}-e^{-r L}\right]}{r}\right]}{\left[\frac{e^{-(r-g) a}-e^{-(r-g) \bar{T}}}{(r-g)}\right]} .
$$

Unlike the indexation case the solution for $\alpha$ will now depend on the actual values taken by $r$ and $g$. With full indexation, when $(r-g)=1 \%, \alpha=16.1 \%$, and when $(r-g)=2 \%, \alpha=12.9 \%$. Holding $(r-g)$ at these two levels the following table shows the values of $a^{*}$ necessary to finance an unindexed pension for various combinations of $r$ and $g$, all the assumptions on which the earlier calculations are based being maintained.

Table 6.1

\begin{tabular}{|llcc|}
\hline$(r-g)=1 \%$ & & $\alpha^{*}$ & Cost of indexation \\
$r=5 \%$ & $g=4 \%$ & $12.9 \%$ & $24.8 \%$ \\
$r=10 \%$ & $g=9 \%$ & $10.4 \%$ & $54.8 \%$ \\
$r=15 \%$ & $g=14 \%$ & $7.9 \%$ & $103.8 \%$ \\
$r=20 \%$ & $g=19 \%$ & $6.6 \%$ & $143.9 \%$ \\
$(r-g)=2 \%$ & & $\alpha^{*}$ & Cost of indexation \\
$r=5 \%$ & $g=3 \%$ & $11.0 \%$ & $17.2 \%$ \\
$r=10 \%$ & $g=8 \%$ & $8.7 \%$ & $48.3 \%$ \\
$r=15 \%$ & $g=13 \%$ & $6.8 \%$ & $89.7 \%$ \\
$r=20 \%$ & $g=18 \%$ & $5.6 \%$ & $130.3 \%$ \\
\hline
\end{tabular}

In both of these examples, when the rate of earnings growth is fairly high the contribution rates can be cut quite drastically if pensions are not indexed. This can be seen from the calculated cost of indexation, which is the ratio of the contribution rate with indexation to that without indexation minus one, expressed as a percentage.

One possible implication of these results is that if funds find themselves with the type of financial problem just described, rather than topping up the pension fund to meet the unanticipated increases in liabilities, the extent of indexation can be reduced. This does not imply that pensioners will suffer the full ravages of inflation. In Britain, at least at present, the State underwrites the indexation of a significant proportion of the private pension paid to the average recipient. It is the discretionary indexation that can be squeezed.

\subsection{Social insurance pensions}

So far, attention has been focused upon the implications of the analysis for private pension schemes. However, there may be spillover effects into the State sector. In 1978, a new State Earnings Related Pension Scheme (SERPS) was introduced in the UK. Full members of SERPS pay earnings related contributions, as do their employers, 
based on earnings below an upper limit, unless their earnings are below a lower earnings limit, in which case contributions are voluntary. The pension received by those with a full contribution record consists of a basic component, equal to the lower earnings limit, and an earnings related component. Private pension schemes which satisfy certain conditions of adequacy can contract their members out of the earnings related component of SERPS. A reduced contribution is then paid by both employees and employers. If a private scheme is contracted out of SERPS, the State nevertheless undertakes an obligation to index that part of the private pension which is equivalent to the pension that would have been payable to an employee had he remained in the State scheme. Both the basic component and the earnings related component are indexed by the change in the retail price index.

Although a large number of factors come into play in reaching a decision whether or not to contract-out of the earnings related component of SERPS, assume that they reduce to a comparison of the rates of return offered as a result of leaving or remaining within the scheme. If private schemes find that they have liabilities in excess of the funds accumulated to meet them, and they respond to this not by topping up the fund but by a method which implies a lower rate of return to pension contributions, then the outcome of the above comparison may take on a different meaning. This is because the overall rate of return to the combined contribution to both State and private schemes has changed. Such a calculation based on more realistic rates of return than those originally employed may reveal that not only is contracting-out no longer worthwhile but also that it never was. The raising of contribution rates, and less generous benefit formulas, including the reduction in discretionary indexation of benefits, both depress rates of return in private schemes.

The implications of fairly widespread contracting back into SERPS are two-fold. Contracted-out individuals still make earnings related contributions to the State scheme. A popular view is that these are set at a level which is sufficiently low to induce fairly widespread contracting-out while at the same time raising enough revenue to enable the scheme to possess considerable redistributive potential. Typically, those who are contracted-out will be the better paid, and if large numbers rejoin the State scheme then the fact that they will do so with near maximum potential benefit entitlements will not only put a considerable drain on the scheme, and force up contribution rates, which has to be allowed for in the comparison of contracting-in and contractingout, but will also make it less egalitarian.

The State scheme operates on a pay-as-you-go basis while most private schemes are funded. If some employers are persuaded that it is no longer worthwhile operating a private pension scheme then savings will initially fall by the amount of the contributions that were previously made but now accrue as income to the individual, on which tax, including higher SERPS contributions, has to be paid. This income may be diverted into some other tax advantaged savings plan, saved in another way or spent. Which of these happens, and the extent of the substitutability between various types of savings, will determine the eventual impact on national savings. Should they fall, and this seems the most likely outcome, then it is clear that the choice of actuarial basis has possible implications which reach beyond those concerned only with the financial 
adequacy of the pension funds. The fullest range of these implications has hardly been touched upon.

\section{Concluding comments}

In this paper, it has been shown that the views that can be formed about the finances of a private pension scheme are very sensitive to the set of economic assumptions chosen. Indeed, they are far more sensitive to these than to the actuarial assumptions made. Yet the deciding of both sets of assumptions is the preserve of the actuary. While actuaries may be very capable when it comes to determining appropriate mortality and retirement rates, there is no reason to believe that they can predict the inflation rate and future rates of return any more successfully than anybody else. And if after reading a typical actuarial report to a pension fund the opinion was held that the actuary's assumptions do not exactly inspire confidence, this would not be unjustified. However, the aim of this paper is not to incite a campaign of vilification against the actuarial profession. There is no evidence of any intention to mislead employers and scheme members. But their unquestioning acceptance of financial advice based upon an overly optimistic view of the world could have very similar consequences. 